\title{
Establishing a Real-Time Multimedia Link to the Arctic ${ }^{1}$
}

\author{
Mark León \\ Project Manager, NASA Learning Technologies \\ M/S 269-3 \\ Moffett Field, CA 94035-1000 \\ $650604-6498$ \\ mleon@mail.arc.nasa.gov
}

Abstract-In July 1998, the NASA Learning Technologies (LT) Project and the United States Coast Guard (USCG) implemented a real-time multimedia link between the USCG Cutter Polar Star in the Gulf of Alaska and schools in the United States and Japan. The Polar Star implemented a mobile high-speed data link connected to the Internet using Inmarsat via Intelsat $178^{\circ} \mathrm{E}$. This link utilized satellite and high-frequency communication links to the NASA Learning Technologies Channel (LTC) to conduct the Internet-based educational events. The NASA LTC is a media for distributing video and audio to 1500 sites worldwide over the Internet.

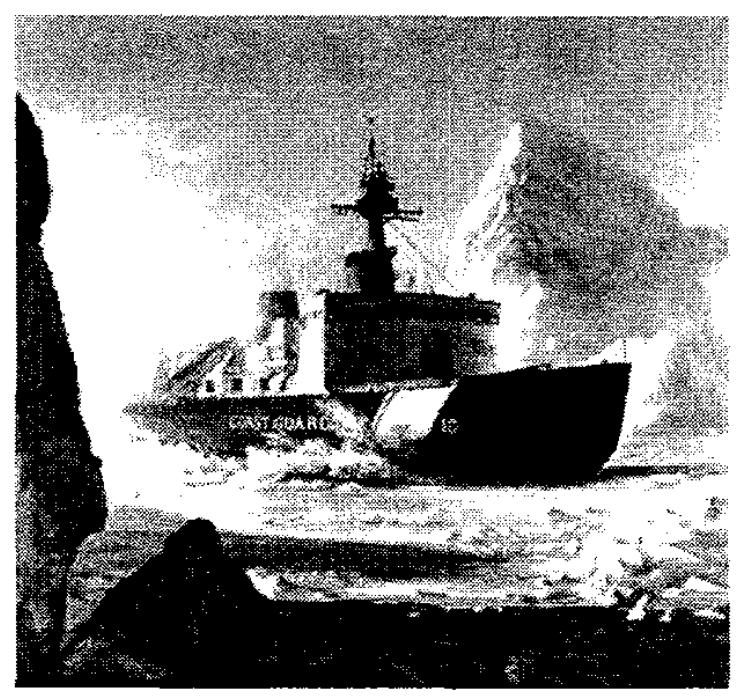

CONTENTS
1. INTRODUCTION
2. BACKGROUND
3. IMPLEMENTATION OF LEARNING TECHNOLOGY

CHANNEL VIA INMARSAT

4. IMPLEMENTATION OF INMARSAT BP AND LTC Mm JULY 1998

5. IMPLEMENTATION OF INMARSAT B ONBOARD THE POLAR STAR-LATE JULY 1998

${ }^{1}$ U.S. Government work not protected by U.S. copyright.

\author{
6. IMPLEMENTATION OF INMARSAT BP ONBOARD THE \\ POLAR STAR-EARLY AUGUST 1998 \\ 7. IMPLEMENTATION OF CONTINENTAL U.S. \\ CONFIGURATION \\ 8. IMPLEMENTATION OF ROUTER CONFIGURATIONS \\ 9. IMPLEMENTATION OF WIRELESS ROUTER \\ CONFIGURATIONS \\ 10. PROBLEMS, MAKESHIFT IMPLEMENTATION, AND \\ CONFIGURATION BREAKTHROUGHS DURING LIVE EVENTS \\ 11. DATA ANALYSIS \\ 12. CONCLUSION
}

\section{INTRODUCTION}

On July 27th, 1998, the National Aeronautics and Space Administration's (NASA) Learning Technologies (LT) Project and the United States Coast Guard (USCG) implemented the world's first real-time multimedia link between the USCG Cutter Polar Star (Polar Star) located in the Gulf of Alaska and schools from as far west as Japan across the entire United States. This link allowed students to enjoy the benefits of leading-edge technology. The effort was built upon LT's existing cadre of technology and was taken to a new height when placed aboard the Polar Star. The Polar Star was the second U.S. ship to implement a mobile high-speed data link connected to the Internet using Inmarsat via Intelsat $178^{\circ}$ E. This technology was further developed to produce events from Ice Station Sheba located at $79^{\circ} \mathrm{N}$.

Learning Technologies implemented several different network configurations within a short time to accommodate requirements for both live broadcasts and scientific experimentation with a remotely operated underwater vehicle. The problems encountered and the solutions developed in establishing a communications network in a harsh and isolated environment working with damaged equipment provided valuable insights into the conditions space explorers will encounter in planetary exploration. These ground-breaking efforts have enabled subsequent breakthroughs in technology applications, education and telepresence. 
NASA LT engineers at Ames Research Center (ARC) in California have implemented three different communication configurations in the Arctic to date: two were part of LT's mobile baseline technologies and one was a response to a request by the USCG. The objective was to implement a high-speed data platform onboard a ship in the high latitudes of Arctic Ocean in order to provide NASA educational events using the Internet. The design included several platforms of multimedia applications run over the Internet as well as redundancy to ensure land-based fallback capabilities over satellite and/or phone lines. Once the events were delivered to the U.S. via the Internet, the primary delivery mechanism was NASA's Learning Technology Channel which can serve thousands of schools with audio events or hundreds of sites with audio and video.

The communication plan for the educational events included a 56-kbps satellite data link for Internet service. An experiment simulating operation of a beta system was conducted in June1998 in Half Moon Bay, California. In July, the USCG presented an urgent requirement to move up the scheduled departure date of the Polar Star. Because of the shortened deadline, LT engineers worked around the clock to implement the requirement. The effort to establish the real-time multi-media link is described below.

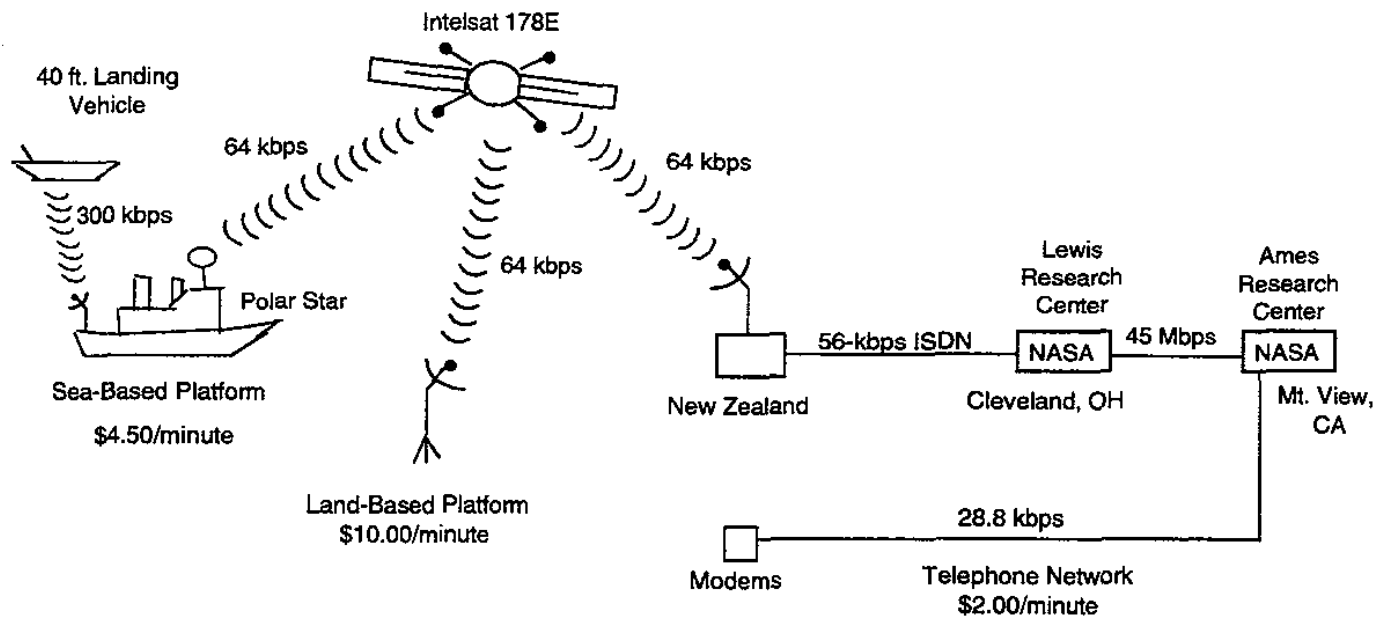

Figure 1 Overview of Arctic Multimedia Circuit

\section{BACKGROUND}

In December 1997, LT management met with the USCG to discuss NASA's Arctic communication requirements for 1998 and 1999. At that time, LT determined that high bandwidth would be required to support compressed video in order to return multimedia events from a robot exploring beneath the Arctic Ocean. This requirement, coupled with similar data requirements for the Polar Star, warranted sufficient justification for the USCG to upgrade their Inmarsat A stations to Inmarsat B. This would increase their data capability from $9.6 \mathrm{kbps}$ to 64 kbps. During the next few months NASA continued to conduct informal system reviews for science opportunities aboard both the Polar Star and Polar Sea.

The primary element of this technology was the use of an Inmarsat portable satellite link. On October 22, $1997, \mathrm{LT}$ was given urgent short-term requirements to demonstrate NASA's Learning Technology Channel (LTC) to Vice President Gore in Dysart, Iowa. This event was executed successfully within 72 hours of notification. Although a 1.5-Mbps link (T1) was rushed in, network congestion at the local hub and a high error rate contributed to very high latency (delay) on the link. The digitized andio portion of this link demonstration was conducted over phone lines. The video still came over the T1, but with 90 seconds latency due to TCP/IP retransmissions and buffering. A new project guideline was established in order to mobilize and demonstrate our NASA educational events from anywhere on the planet. Designs were laid in place at Lewis Research Center (LeRC), Cleveland, Ohio. Preparations were made to design an Internet link that could nun over a portable Inmarsat Bp station. Design reviews and cost projections drove the cost up to $\$ 60,000$, not including charges for satellite 
time. The project was put on hold pending available funding.

Another short-term requirement, which came almost as quickly as the last, reinforced the need for an Inmarsat Bp. First Lady Hillary Clinton intended to visit a school in Paris, France, to establish a French/American Education project. Authorization was given to implement the LeRC design, but because of the short lead time, it was not feasible to purchase an Inmarsat Bp station. Instead LT had to rent one and configure it with LeRC routers and Integrated Services Digital Network (ISDN) dial-up links. Once again engineers worked through the weekend and sent the package back to ARC. The LT Project Manager then assembled this Internet link with several multimedia stations to implement the NASA LTC overseas.

LT produced a live event from Paris, France, on May 12, 1998, as a demonstration for the First Lady. The multimedia platform broadcast the event to hundreds of people in France and America. The Inmarsat satellite link was used purely as a backup in the event the French link failed, something that had occurred for 20 minutes earlier the day of the event. LT was successful in a complete simulation from Paris using Atlantic satellites, thus proving the concept. This second requirement solidified the need to acquire this technology, and a government procurement was placed for an Inmarsat Bp portable station.

The Polar Star and the Polar Sea were both upgraded and tested for all functions within a very short time. The week of July 13, 1998, Inmarsat engineers and NASA engineers struggled to resolve technical issues with the Inmarsat $B$ high-speed data function. The unique combination of technologies worked easily enough on land, but the slightly different implementations onboard the Polar Star made it difficult to troubleshoot the problems.

\section{IMPLEMENTATION OF LEARNING}

\section{Technology Channel via InMarsat}

One of NASA's key projects is the Learning Technologies Channel. The purpose of this Internet-based multimedia resource is to bring NASA's finest science to the educational community. It is predicated on a series of software platforms designed to carry audio and video out to academia. Coupled with chat windows and slide presentations, this capability represents state-of-theart use of existing modem bandwidths. The system is described below.

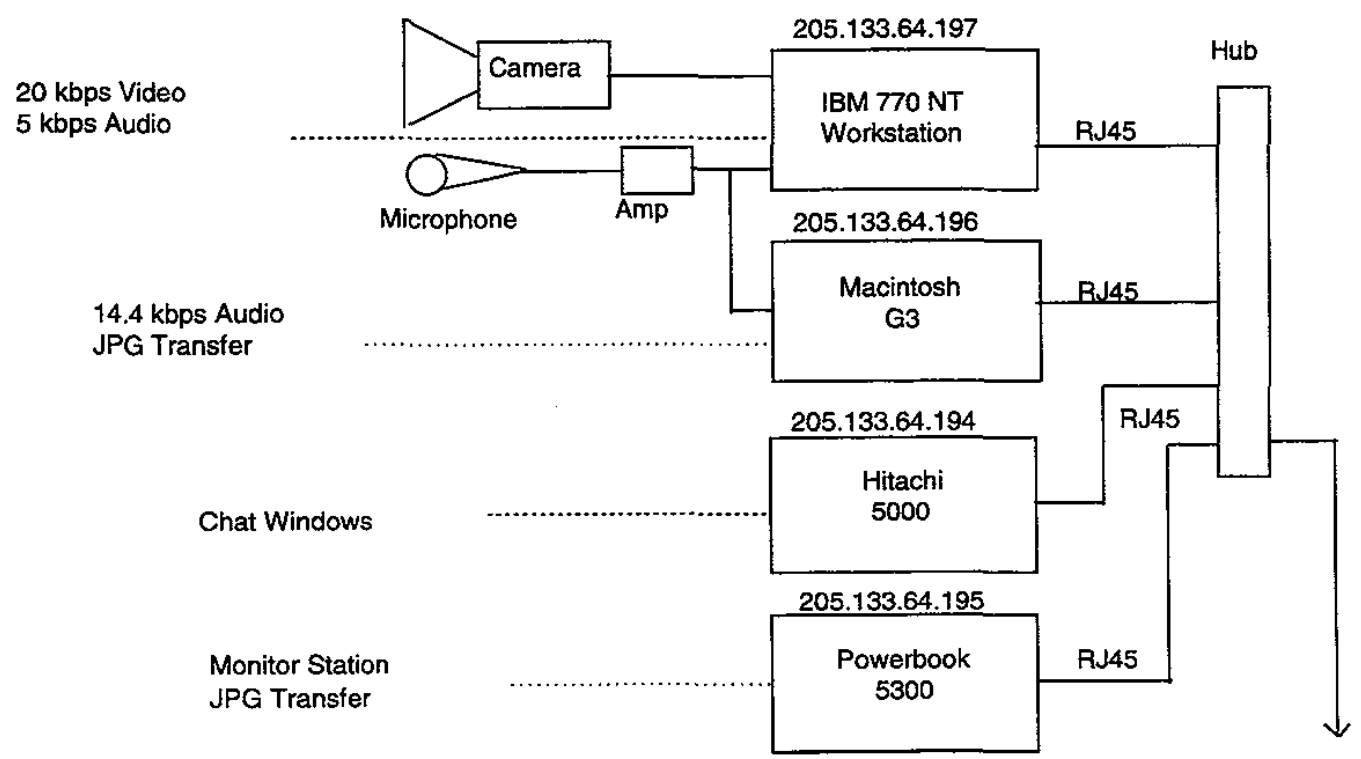

Network

Figure 2 Learning Technology Channel Multimedia System 
The feeds for the multimedia system are predicated on four basic modes. The primary mode is audio, so we provided two streams of audio for the event, a primary and a secondary link. The second mode was video. The video stream at $20 \mathrm{kbps}$, together with the audio stream at $8 \mathrm{kbps}$, made up a RealMedia ${ }^{\mathrm{rM}}$ stream that most Americans could receive over standard modems operating at $28.8 \mathrm{kbps}$. An IBM Thinkpad ${ }^{\mathrm{rM}} 770$ operating as an NT workstation ran this platform. A high-eight video camcorder fed the video source into an Osprey ${ }^{\mathrm{TM}} 1000$ video card. A microphone was amplified by a Genter box and split into the NT workstation and the secondary audio encoder. The backup audio stream ran over RealAudio $^{\mathrm{TM}}$ software and was encoded at $14.4 \mathrm{kbps}$ on a Macintosh G3 portable.

The third mode was the use of a Hitachi 5000 portable to operate the chat window. This unit was to act as our method of receiving questions from students. We received questions from as far as Japan to the U.S. East Coast during these events. Users received text status information when the productions encountered technical difficulties or if their questions were out of scope for a particular lecture.

The last mode of this configuration was the collection of JPEG images. Users were able to look at still images, as they had been taken only hours earlier from the Arctic adventure. These pictures were even more important when video was inoperative.

The Powerbook ${ }^{\mathrm{TM}} 5300$ in the above configuration was a support machine in case the Hitachi station failed during chat sessions. All of these machines were patched onto an Ethernet via a 4-port hub. The hub then connected directly to the router for Inmarsat B portable configurations. In Inmarsat B configurations, the hub used the ship's local area network (LAN) to reach the router.

\section{IMPLEMENTATION OF INMARSAT BP AND}

$$
\text { LTC-MID JULY } 1998
$$

On July 13, 1998, it became apparent that our Inmarsat Bp procurement would not occur on schedule. Although this procurement was originally intended for a Russian robotics experiment, we had adjusted requirements to expedite its procurement to satisfy the USCG mission. Also, due the experimental nature of this link, it was entirely possible that we would not be able to get the ship's Inmarsat operational prior to departure on July 24. We needed the portable Inmarsat Bp station as a backup for land-based communications.

We turned to Wang Inc., one of NASA's support service contractors, and asked them to rent another Inmarsat $\mathrm{Bp}$ as they had for the event with the First Lady. Within a few days we had the equipment, including a brand new Cisco 2514 router. Our job was to configure the Inmarsat $\mathrm{Bp}$ station and the router to function exactly as they had for the event in Paris earlier that year. We were confident that this would not be too difficult, but that was not the case. This new technology had not been widely used and there was very little expertise available to solve these problems. When problems began to arise, we put NASA's networking experts on the problem. Together, LeRC and ARC resolved the problems over a number of days and many hours of work. 


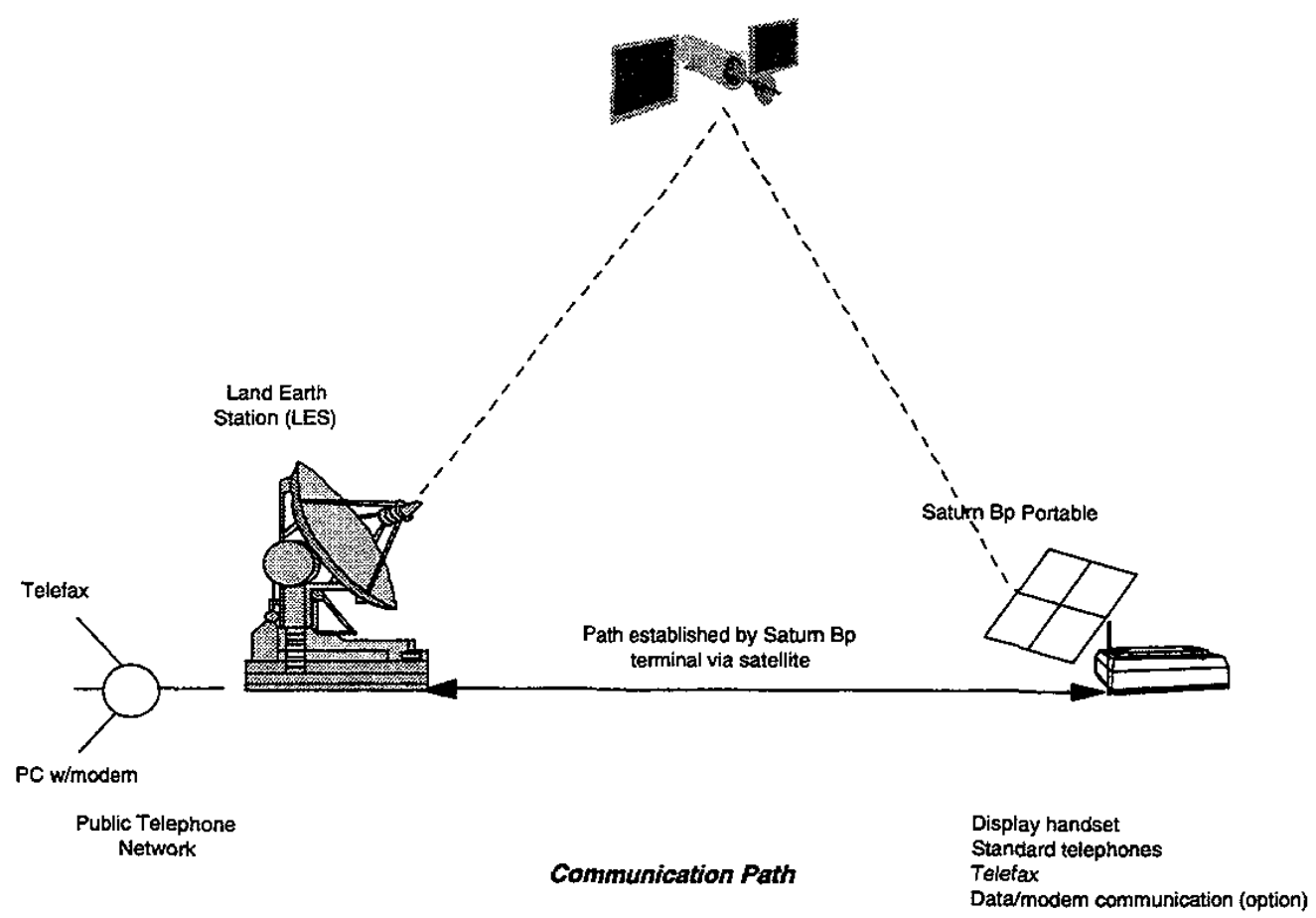

Figure 3 Generic Land-Based Setup

The first set of problems occurred when the Mobile Earth Station (MES) would not connect to the Pacific Ocean Region satellite Intelsat $178^{\circ} \mathrm{E}$. After troubleshooting, it became apparent that we did not have our ground station configured correctly. To make things worse, the rental company did not provide us with root access, and without that we could not change the configuration. When the access password was provided by the owner, we were able to operate the system for voice and data. It was possible to operate the system in High Speed Data (HSD) mode at 64 or $56 \mathrm{kbps}$ in a loop-back configuration. Unfortunately it took another 48 hours to solve a routing problem between the Cisco routers in California and Ohio.

One of our major problems was the configuration of the ISDN switches in the Land Earth Stations (LES) in New
Zealand. We found that some LES use $64 \mathrm{kbps}$ and some use $56 \mathrm{kbps}$ - the secret in this case was to configure everything for $56 \mathrm{kbps}$. It seems like an obvious point, but when you can't tell what happens after the signal leaves your Inmarsat station, all you know is that it doesn't work at the other end.

This was an interesting point. In order to send out TCP/IP packets, we had to use a router and run Point-to-Point Protocol (PPP). The router then communicated to the Inmarsat $B p$ station via $R S-232$ running V.25 bis. Once the data leaves the Inmarsat $\mathrm{Bp}$, it travels $35700 \mathrm{~km}$ via L-Band $(1.5 \mathrm{Ghz}$ to $1.6 \mathrm{Ghz})$ to the orbiting satellite. In our case that was Intelsat $178^{\circ} \mathrm{E}$. From there it communicates with an LES via C-Band ( $4 \mathrm{Ghz}$ to $6 \mathrm{Ghz}$ ). At this point it leaves the LES via an ISDN to LeRC in Ohio. 
Portable Based High Speed Data Configuration (HSD)

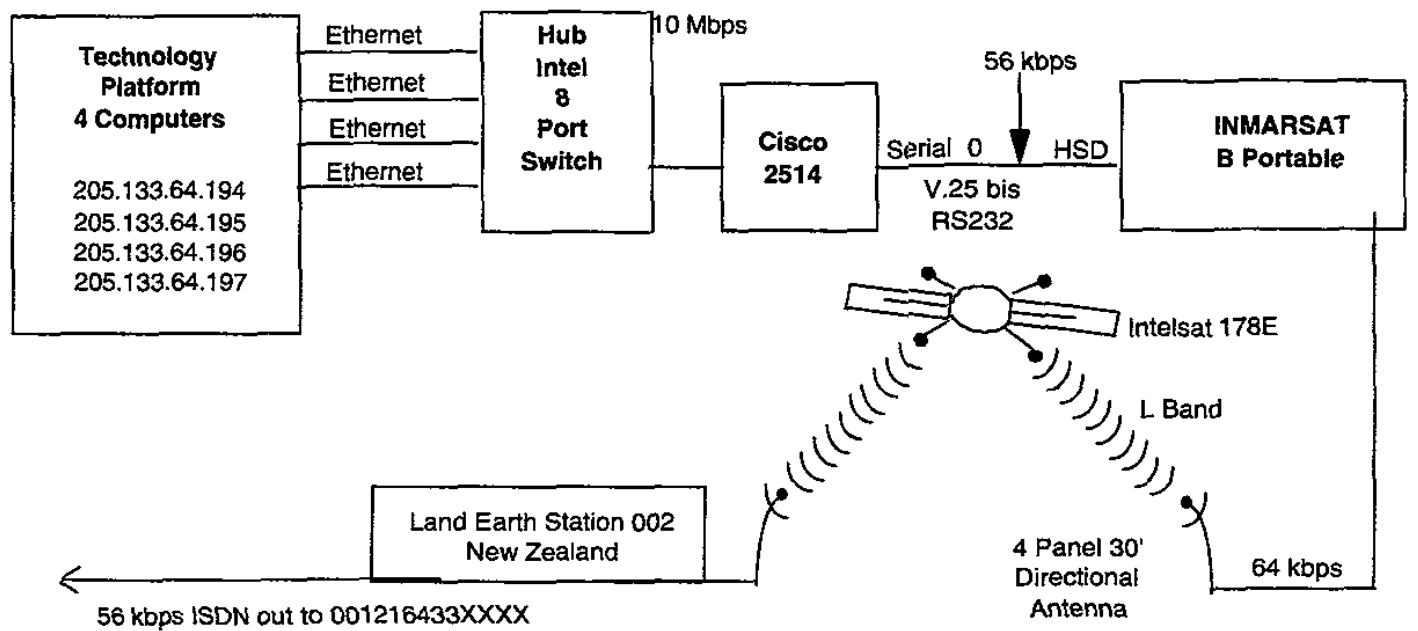

Figure 4 Generic Land-Based System Diagram

\section{IMPLEMENTATION OF INMARSAT B ONBOARD}

\section{THE POLAR STAR-LATE JULY 1998}

On July 24, NASA was successful in implementing Inmarsat HSD on the Polar Star. To date the only other
U.S. government ship to have full Internet access at this speed was a NOAA vessel with their connection coming online only two weeks prior. Several problems came into play during this implementation. 


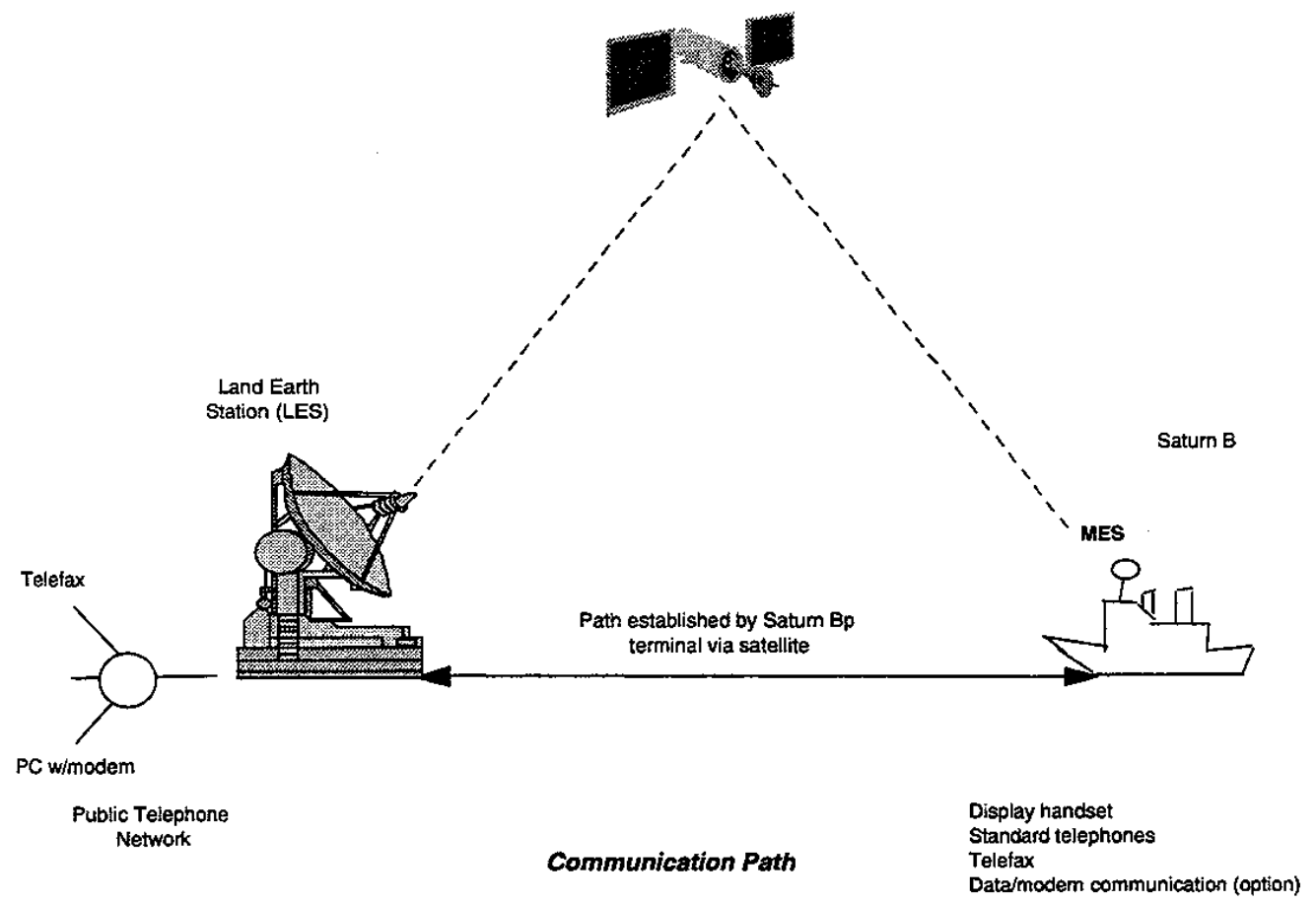

Figure 5 Generic Sea-Based Setup

The previous week a subcontractor had installed the Inmarsat B station into the Polar Star. They had tested out most of the systems with the exception of the HSD as they had no Internet service provider to support it. NASA sent up two engineers to work with the subcontractor. The team worked for three days and was unable to resolve the problem. Loop-back tests with the HSD circuit indicated that the system was working correcting from COMSAT's perspective.

The following week on July 22, the NASA Project Manager, his Arctic communication team and another NASA engineer arrived onboard the Polar Star and began to work on the same problem with no luck. Working through the night testing every imaginable configuration for the Cisco routers, ISDN switch at LeRC and all other support equipment it was clear that the ISDN lines were connecting briefly but not able to establish a session. It was later revealed that mismatches in program configurations between pieces of the links led to this problem. In the end we configured all equipment to operate at $56 \mathrm{kbps}$, even though the link was designed for $64 \mathrm{kbps}$. This was because certain parts of the transcontinental link would only carry traffic at $56 \mathrm{kbps}$. This piece was transparent to our engineers until the end of the trouble hunt.

From an operational standpoint the major difference between the ship- and land-based units was the requirement to use manual dialing when connecting from the ship to Inmarsat. On land the router would automatically dial when an IP address was accessed outside of its domain. 
Ship Based High Speed Data Configuration (HSD)

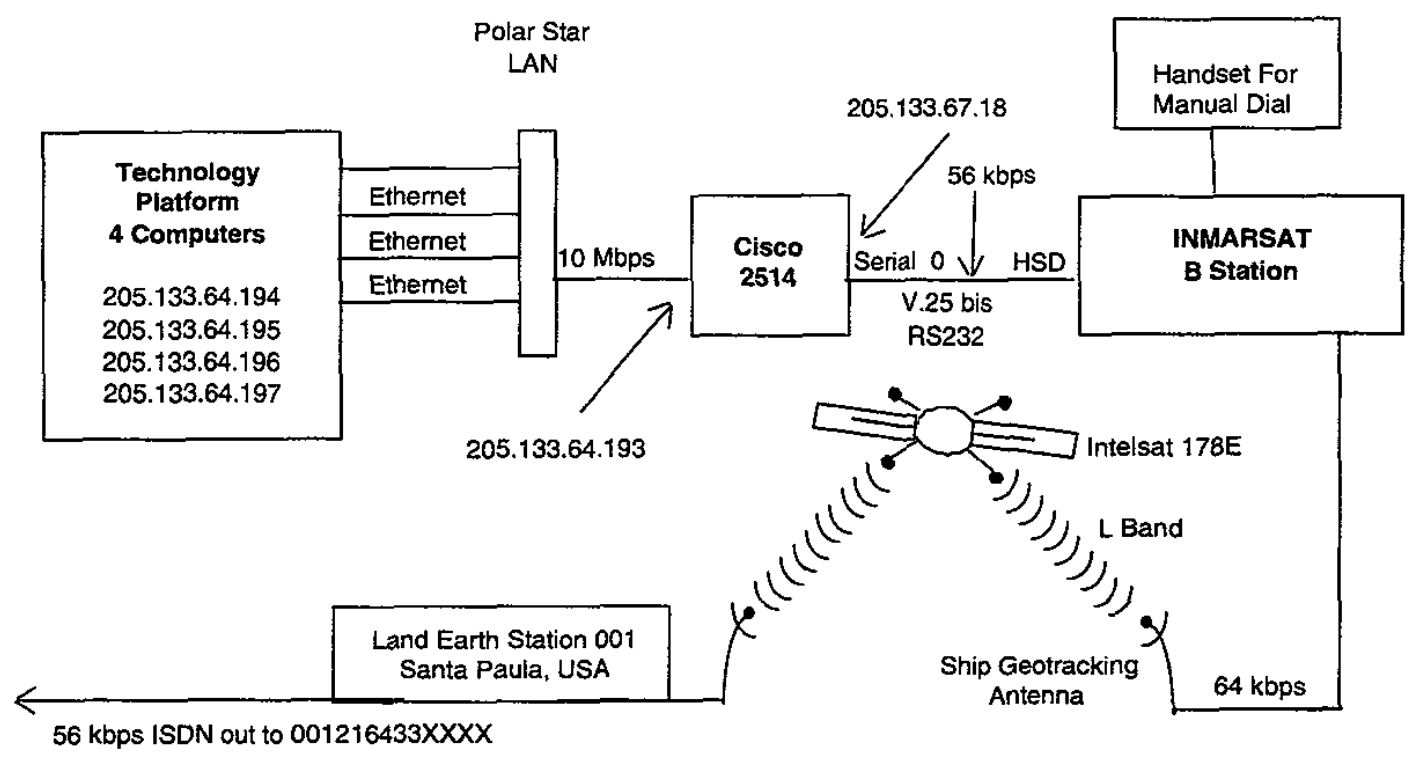

Figure 6 Generic Sea-Based System Diagram

\section{IMPLEMENTATION OF INMARSAT BP \\ ONBOARD THE POLAR STAR-EARLY AUGUST 1998}

On July 26, during set-up for our second live broadcast, a major problem caused us to rework how we would do all of our live broadcasts. At a mere $56^{\circ} \mathrm{N}$., our ship's Inmarsat B HSD began to fail. With connection times lasting only several seconds, it became clear that we would not be able to conduct a live broadcast with our design of choice.

A quick decision to see if our land-based unit would work on the deck of the Polar Star saved the day. With only minutes remaining, the NASA technicians successfully deployed the Inmarsat B portable on the deck of the flying bridge. With a simple swivel chair placed below the dish, one of the NASA technicians manually tracked the satellite using a compass and signal strength readings from the handset of the Inmarsat $B$ portable. The signal strength we had seen in the field ranged from 0 to 500 . During this broadcast we were able to maintain a healthy average of around 70. From our experience, anything below 50 would cause the TCP/IP connection to drop. Additionally, we could obtain the Bit Error Rate. It again occurred numerically between 30 and 60. Statistically anything above 45 would cause the TCP/IP to begin to fail. If it didn't fail, the effective bandwidth of the circuit approached that of the older 9.6-kbps modems.

\section{IMPLEMENTATION OF CONTINENTAL U.S.}

\section{CONFIGURATION}


NASA CONUS Station Configuration

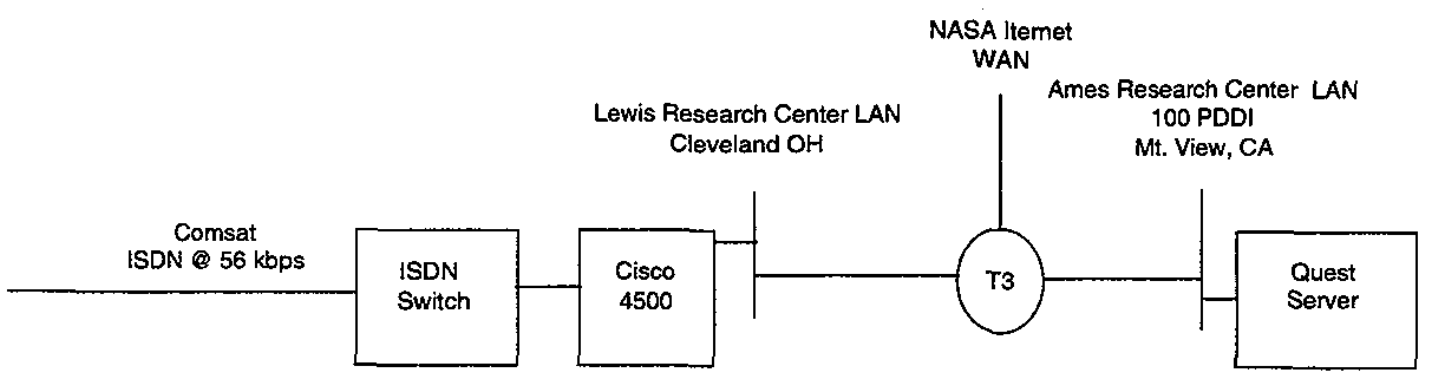

Figure 7 NASA Continental U.S. Configuration

\section{IMPLEMENTATION OF ROUTER}

\section{CONFIGURATIONS}

In early May, LeRC engineers Gib Winter and Beth Lewandowski implemented the Continental United States backbone that would support all of our Inmarsat operations. We understood that this had been accomplished before, but Inmarsat couldn't point us to any other users who knew how implement the required design. Both engineers worked day and night for about nine days to establish the correct router/ISDN configuration. The basic concept involved an ISDN call coming in from overseas and connecting to an ISDN switch in Cleveland, Ohio. From Ohio, PPP was used through a Cisco router to NASA's wide area network (WAN). Over this WAN, the TCP/IP streams moved to ARC in Mt. View, California, where it was supported by multimedia servers. A backbone of NASA RealMedia ${ }^{\text {TM }}$ servers was then fed across the nation making thousands of streams available to the educational community.

The biggest roadblock concerned the ISDN/Inmarsat configurations and bandwidths. Typically we used an LES in New Zealand which piped directly into a 56kbps ISDN line. Earlier configurations in the international pipe were expecting $64 \mathrm{kbps}$. This mismatch caused clocking problems and a general inability to make a connection. The HSD call would connect, hang for a moment while the router attempted to accept the ISDN connection, and then drop after synchronization problems occurred. The Inmarsat used a V.25 bis over an RS-232 synchronous link operating at $64 \mathrm{kbps}$ or $56 \mathrm{kbps}$. To solve the problem we dropped everything down to $56 \mathrm{kbps}$ and used an LES that supported only $56 \mathrm{kbps}$. Although loop-back tests through England worked well, we weren't able to use the same LES at $56 \mathrm{kbps}$. Also, earlier LES connections made through Canada and Australia were using 64-kbps ISDN connections which seemed to conflict with our 56-kbps ISDN switch. In the end, we found the right set of configurations for the Cisco 4500 router. (See appendix A.)

\section{IMPLEMENTATION OF WIRELESS ROUTER}

\section{CONFIGURATIONS}

On, July 15 , we were informed that our support platform Polar Star would be departing two weeks earlier than planned. This posed a problem as we still hadn't acquired our wireless bridges. Fortunately, the USCG Science Liaison, Phil McGillivary, had already designed a solution to support a flotilla of ships to interlink vessels at sea within 20 miles of each other. This wireless technology proved to be very robust, and with the help of Phil's contacts, we obtained the required wireless routers. The wireless routers had to be the correct routes, and any computers located at the end of the remote router had to be reconfigured. While these routers were more complicated to use than wireless bridges, they were much easier to troubleshoot. We could easily ping our way through the network until we found the problem.

As always, most problems could be attributed to bad Ethernet connections. The wet, cold and austere environment was very hard on the connections between these devices. Nevertheless we managed to pick up students ranging from Japan to Eastern United States to Puerto Rico. 


\section{PROBLEMS, MAKESHIFT}

\section{IMPLEMENTATION, AND CONFIGURATION}

\section{BREAKTHROUGHS DURING LIVE EVENTS}

The following 14 events were scheduled to test the intricate Internet system. They were also designed to provide valuable NASA scientific content to the educational community. The greatest drawback was that these tests fell between summer school and regular session, thus reducing student participation.

Event $56^{\circ}$ N. $139^{\circ}$ W., July 25 (Captain Lancaster Interview): At $56^{\circ} \mathrm{N}$. by $139^{\circ} \mathrm{W}$. in the Gulf of Alaska we conducted our first interview with Captain Lancaster. The transmission went flawlessly. The ship's Inmarsat system was all that it was promised to be. The seas were moderate and the antenna kept the signal lock for the entire broadcast. We were filled with high hopes that all of our broadcasts would go as smoothly. The interview can still be viewed in its archived form at http://quest.arc.nasa.gov/arctic. People participated from Japan to the East Coast of the U.S.

Event $55^{\circ} \mathrm{N} .156^{\circ} \mathrm{W}$., July 26 (Lt. Sharp Interview): At $55^{\circ} \mathrm{N}$. by $156^{\circ} \mathrm{W}$. bound north for Nome, we commenced set-up for our second interview at sea with the senior female officer aboard the Polar Star. While email tests had worked earlier that morning, systems were now unable to keep a satellite lock for more than a few minutes. With this devastating blow to our expectations, we quickly deployed the Inmarsat B portable aboard the flying bridge, the area located above the bridge. It is one of the highest places on the ship with the exception of the Crow's Nest which was five stories higher but almost impossible to deploy to. We placed the Inmarsat portable on a swivel chair (Mr. Seth Carter's idea) and successfully tracked the signal strength. A liquid crystal display on the Inmarsat B portable phone could be set to measure signal strength. As the ship turned, NASA technicians tracked the satellite's location. Once again we had a flawless event, but just barely. It had become apparent that these live broadcasts were going to be no easy matter.

Event $56^{\circ}$ N.152 $2^{\circ}$ W., August 1 (Impressions of Kodiak Island, Alaska): At $56^{\circ} \mathrm{N} .152^{\circ} \mathrm{W}$. we had turned back to Kodiak Island, Alaska, for Polar Star operational reasons. We took advantage of this opportunity and deployed our equipment to the top of Kodiak Island as the dock was located under a large mountain that blocked the satellite.
As the Coast Guard enlisted men dropped us off, they asked if we had a gun to fend off Kodiak Bears. We had overlooked this detail and decided to keep one person on watch while the others worked on deploying the equipment. The Inmarsat signal was powerfully strong and we were happy that our infrastructure was in place. As fate would have it, our NT portable decided not to recognize the Ethernet port. Apparently the portable really wasn't that portable. We were unable to fix the problem on top of the island, so we switched to our backup audio-only link which was encoded by the G3 Macintosh. Viewers were very complementary of the good quality of the $14.4-\mathrm{kbps}$ stream that the unit produced. Normally we used a 5kbps stream to accompany the 20-kbps video stream as a package to keep bandwidth at $25 \mathrm{kbps}$. The event occurred on schedule, but without video. Our generators worked well and we had no use for our 110 $\mathrm{AC}$ battery system. Aside from sunburn, we were not eaten by bears.

Event $62^{\circ} \mathrm{N} .167^{\circ} \mathrm{W}$. , August 6th (Impressions of Nome, Alaska): Finally at Nome, we deployed on the beach and were freezing. The locals didn't speak English and I didn't speak Inuit, so they kept walking in front of our antenna dish. I didn't know how to tell them about the hazard area extending four meters in front of the flat panel display that radiated out in a 30degree pattern. I resorted to hand language and got the message across. All equipment functioned excellently, but as we were so cold, we could hardly type into the chat window to check for questions. Ten minutes into our broadcast, our RealMedia ${ }^{\mathrm{TM}}$ stream was overwritten by a previously scheduled NASA event, and so ended the Nome Broadcast. The biggest problem was that we arrived a day later than we had scheduled the event, and while we had a small group of loyal followers, the delay of being deployed by helicopter cost us most of our viewers. The final point is that it is very difficult to schedule events when you are second to an operational mission that has priority. We did the best we could.

Event $66^{\circ} \mathrm{N} .168^{\circ}$ W., August 7 (Interview with Dr. Tucker bound for Sheba): At $66^{\circ} \mathrm{N}$ by $168^{\circ} \mathrm{W}$ we attempted to interview the next senior scientist, Dr. Tucker, bound for Ice Station Sheba. We had picked up Dr. Tucker along with 30 other men and women destined to relieve the current Sheba crew. Freezing temperatures of minus $20^{\circ} \mathrm{F}$ coupled with snow made our physical experience difficult. The technicians were loyally working the NASA equipment on the roof while I interviewed the senior scientist below. Intermittent conditions only allowed our broadcast to continue for 10 minutes before going down hard for the rest of the night. Just a note-during the summer the 
sun doesn't set, so you can always set up your equipment on deck.

We then went down to the ship's Inmarsat phone which still worked despite the HSD failure. We completed our interview via telephone, where the conversation was encoded in Mt. View and placed onto the Internet. We used a Getner box to patch a mic into the phones input. I used the headset to listen for questions as they were read off of the chat windows in California. We were able to complete the whole interview with audio only going out to the schools.

Event $78^{\circ} \mathrm{N} .159^{\circ}$ W., August 12 (Dr. Petrovitch Interview, Ice Station Sheba): At $78^{\circ} \mathrm{N}$. by $159^{\circ} \mathrm{W}$., we reached Ice Station Sheba. Although the equipment was rated to operated reliable only up to 70 degrees North and South, we were determined to get ours to work. The Canadians aboard Sheba had a high speed Inmarsat system working as well, and they reported that ionospheric conditions sometimes caused them hours of blackout periods.

We attempted without success on August 13th at $77^{\circ}$ N., and 14 th at $76^{\circ} \mathrm{N}$., to hold this event. Each day we would attempt to interview the senior scientist of Ice Station Shieba, Dr. Petrovitch, who had just completed a tour of duty. Each day our network could only come up for a few minutes at a time. On the second day, a run of 12 minutes led us to believe that we might be able to conduct our interview. Over the three-day period viewers drop dramatically with only a hand full willing to watch the event by the third day. On our last attempt, we tried to implement a phone link using the ship's Inmarsat but were unable to keep a phone link up. Alas, mother nature had won this round.

Event $71^{\circ} \mathrm{N} .156^{\circ}$ W., August 17, (Mr. Bates Impressions of Pt. Barrow): With land in view and positive test results from the day before, we attempted to execute our scheduled event for August 17. Mother nature only granted us only a 10 -minute broadcast. The viewers got a taste but we were unable to answer any of the questions we received over the chat windows as the system did not come up.

False hopes had risen briefly as the ship's Inmarsat B HSD decided to function for seven minutes, thus casting aside our theories that the ship's satellite tracking capability was insufficiently focused on Intelsat 178 to allow for an HSD connection. This brief moment wasn't to be duplicated for a number of days. Still, every day we attempted to raise the link with the ship's antenna without success. When the link came up I nearly fell over.
Event $74^{\circ} \mathrm{N} .145^{\circ} \mathrm{W}$, August 19th, (Remote Boat Test I): Two NASA technicians were deployed aboard a landing vehicle similar to the ones they used to storm the beaches in World War II. We deployed our wireless routers and established a link. Operating at a radio frequency of $2.4 \mathrm{Ghz}$ we connected to our equipment aboard the Polar Star at a range of $6.5 \mathrm{~km}$. The severe cold $\left(-40^{\circ} \mathrm{F}\right)$ made working in this environment very uncomfortable. The equipment is tested to operate up to $32 \mathrm{~km}$ under ideal conditions. The Inmarsat $\mathrm{Bp}$ was operational but we could not communicate back to the U.S. due to bad cables between the wireless router aboard the Polar Star and our Inmarsat Bp. As I was deployed in a field of floating icebergs, I was unable to troubleshoot the problem onboard the Polar Star until we later returned. Ship-to-ship tests were excellent, but we were unable to complete the primary test objective during this test.

Event $70^{\circ} \mathrm{N} .158^{\circ} \mathrm{W}$., August $23 \mathrm{rd}$, (Remote Boat Test II): This next test of the landing craft was implemented in waters that were so rough that the other NASA robotics team was unable to deploy their remotely operated vehicle. Problems with the configuration made it necessary to reconfigure the IP addresses at the remote boat. Normally this would be no problem, but the senior technician was seasick and I had to talk the other technician through the procedure over walkietalkie. Finally after a few minutes, we successfully completed the test by downloading data from ARC.

Event $70^{\circ} \mathrm{N} .159^{\circ}$ W., August 24 th (Mr. Ota Lecture): Signal strengths were at an all-time low, never climbing above 40 . Thus it was impossible to execute a live broadcast. Attempts to use Inmarsat phone lines were equally impossible. We archived this interview and digitized it using RealMedia ${ }^{\text {TM }}$ later that night. The 30-minute interview took 14 minutes to download in two pieces when we got the Internet up using the Polar Star's system. Each link would only last for about 7 minutes, but long enough to get the data out. It is unclear why the Polar Star's system suddenly worked again. Logically the ship's antenna is located about 4 meters higher than our portable, and for this reason has superior gain. My own feeling is that the antenna is at times optimally focused at the satellite and during these windows ideal for HSD. The rest of the time their antenna is probably pointing off dead center, allowing for Inmarsat phone calls but not HSD. When the satellite goes out of range, the gryo motors move the antenna back into a better position. The ship's antenna was enclosed inside of a small 1.5-meter raydome. Without being able to look at the antenna 
during its operation it is impossible to know if this was the problem.

Event $70^{\circ} \mathrm{N} .159^{\circ}$ W., August 25th (Dr. Hope Lecture): For both Mr. Ota and Dr. Hope, we filmed the interviews in a location onboard the Polar Star where there was no Internet access, so we deployed our wireless routers to carry the last few hundred meters. While the system onboard was well configured, we were still unable to lock onto a signal for more than two minutes with the portable and five minutes with the ship's system.

Event $70^{\circ} \mathrm{N} .159^{\circ} \mathrm{W}$., August 26th (Mr. Weast Lecture): This was one of our more interesting lectures as it included an in-depth discussion and demonstration of the submersible remotely operated vehicle (ROV) above water. Once again the wireless routers were critical to getting to the ROV's location. Fortunately for us were able to conduct the entire lecture using our portable without problem. We answered 40 questions from students across America. We were at the same location as the previous two days, and we executed the event at the same time-the only variable was the Earth's atmosphere.

Event $71^{\circ}$ N. $156^{\circ}$ W., August 27th (Mr. Durbes Lecture): For this event we patched into the ship's network and linked a computer lab to the Internet so that we could broadcast the three-dimensional modeling work that was being conducted with the data gathered from the ROV. Once again we had an excellent event. Also note we had actually climbed a little farther north.

Event $70^{\circ} \mathrm{N} .159^{\circ} \mathrm{W}$., August 28 th (Lt. Billeaudeaux Lecture): On our last scheduled event the gremlins attacked again and prevented our signal from getting out. This time the ship's system was completely dead and we couldn't raise more than 40 on our portable link. We archived the event and mailed it later that night from our hotel in Pt. Barrow after taking the ship's helicopters back to Pt. Barrow.

General Issues: Several factors made our job more difficult, including lack of resources, the harsh environment, limited power supply, the occultation period that blocked communications, dealing with a large number of demarcs, compensating for the ship's motion, and ionospheric instability.

\section{DATA ANALYSIS}

While typical signal strength along the equator with unblocked signal paths is around 400 , we typically received levels of 60 . When the signal dropped below 45 , we could not hold a TCP/IP connection. Phone calls were even difficult below 40 . The table in appendix B contains our log of values.

These data tell us that as rated, the Inmarsat B portable is hit and miss above $70^{\circ} \mathrm{N}$. as advertised by the vender. Ice Station Sheba had a better linkthey did not have full Internet access, but simple file transfer protocol capabilities.

\section{CONCLUSION}

As a direct result of the Learning Technology's ground-breaking efforts in July 1998, several historical breakthroughs have occurred, not only in technology applications, but in historic "firsts" for education and telepresence-this was the first U.S. government-owned vessel to have full Internet access at high speeds, the first time that live video was sent back from the Arctic via the Internet, and the first time that such an interactive event was demonstrated allowing students to hear the answers to their questions within seconds of typing them into a chat window from one of the most remote locations on Earth.

This technology is not unique; it consists of turn-key technology, self-contained commercially-available systems. What is unique is the system integration that NASA championed. What was unprecedented was NASA's rigor and the innovative fashion in which this historic first was implemented at a time when it was thought to be technically infeasible.

\section{Acknowledgments}

Many people contributed to the success of this event-USCG Science Liaison, Dr. Phil McGillivary who made this opportunity possible; my loyal crew Damien Canerot, Seth Carter and Jamie Silva; Captain Lancaster and the crew of the CGC Polar Star for hosting the NASA team for 38 days at sea; and the tireless effort of the NASA team, Gib Winter, Beth Lewandowski, David Swager, Jeff Schaefer, Dan Scott, Christiy Budenbender, Michael Young, William Likens, and Tom Dyson. Also thanks to NERA Communications, McKay Communications, and Wang, Inc. It has been an honor to work with all of these people, and their efforts have broken new ground for distance learning. 


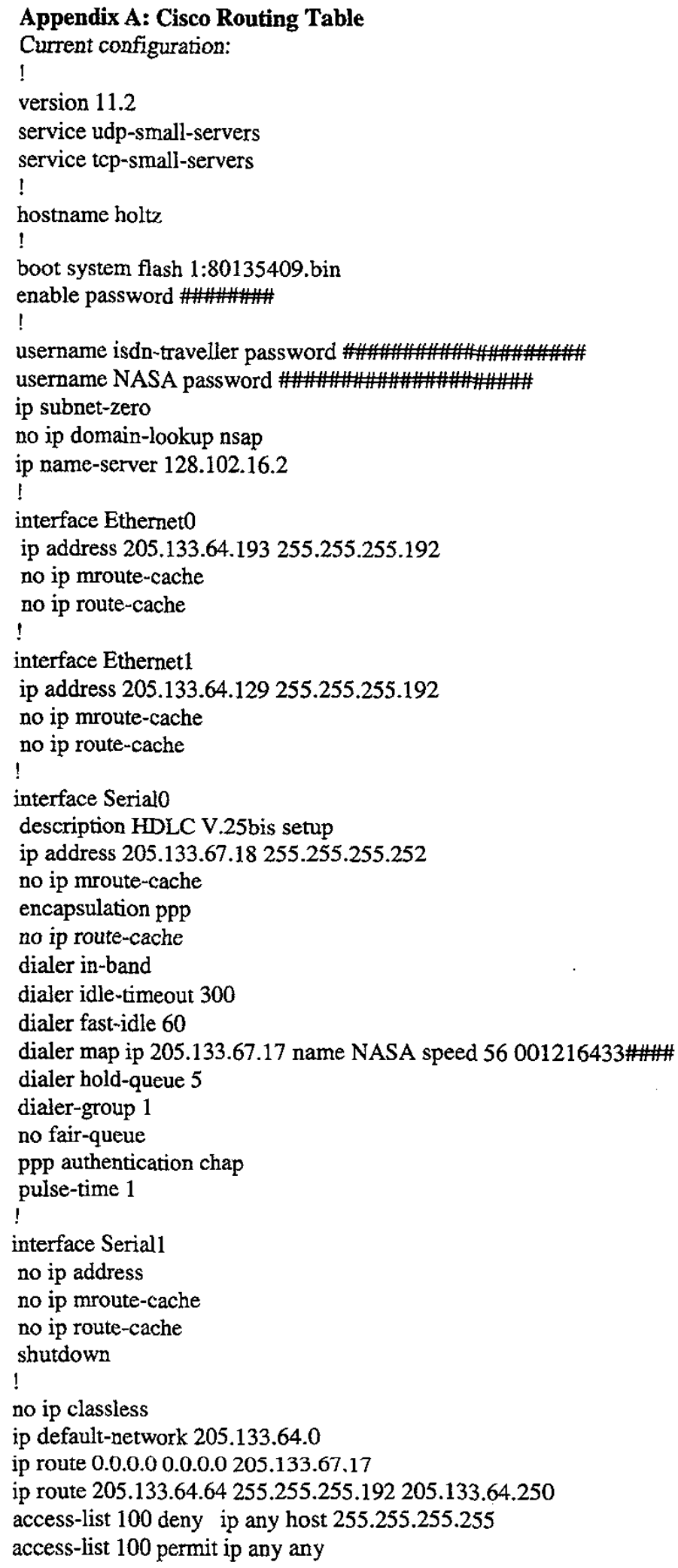


dialer-list 1 protocol ip list 100

$!$

line con 0

exec-timeout 00

line aux 0

transport input all

line vty 04

password \#\#\#\#\#

login

!

end

Global values:

Internet Protocol routing is enabled

Ethernet0 is up, line protocol is down

Internet address is 205.133.64.193/26

Ethernet1 is up, line protocol is down

Internet address is 205.133.64.129/26

Serialo is up, line protocol is up

Internet address is 205.133.67.18/30

Seriall is administratively down, line protocol is down 
Appendix B: Signal Strength Log

\begin{tabular}{|c|c|c|c|c|c|c|c|c|c|c|c|}
\hline Time & Donte & Lntithude & Longthede & Feocing & $\overline{K T S}$ & Event & Conditions & Plution & LAN10 & Signal & Maxtinecon \\
\hline $1200 \mathrm{PST}$ & $22 \sqrt{2}+4$ & $47 \mathrm{~N}$ & $122 \mathrm{~W}$ & Seaftite & Docked & Systems Tast & Lover Sea & Polar Star & 183 & Sat Lock & Urimentupted \\
\hline$\$ 200$ PST & 23 - fid & $47 \mathrm{~N}$ & $122 \mathrm{~W}$ & Seatro & Docked & Systems Test & Leve Sea & Polar Star & 193865 & Set Lock & Unimteruped \\
\hline 1200 PST & 23 sul & $47 \mathrm{~N}$ & $122 \mathrm{~W}$ & Seatto & Docked & Systems Tost & Love' Soa & NASA Portable & 193 & $170-210$ & Unintorupted \\
\hline 2000 PST & $24 \sqrt{\text { Wut }}$ & $48-12.0 \mathrm{~N}$ & $122-50.0 \mathrm{~W}$ & 271 & 8.5 & Systems Test & Calm Sos & Polar Star & 183865 & Sat Lock & Unirtenupted \\
\hline $1200 \mathrm{PST}$ & $25 \cdot \mathrm{Jul}$ & $49.12 .8 \mathrm{~N}$ & $127-01.4 \mathrm{~W}$ & 295 & 12.5 & Esmall & High Sea & Polar Star & 193 & Sat Lock & Unirterupted \\
\hline $1200 \mathrm{PST}$ & $26-\sqrt{u l}$ & $51.5 .8 \mathrm{~N}$ & $133-53.3 \mathrm{~W}$ & 295 & 15.3 & E-mail & Moderate Spa & Polar Star & 193 & Sat Lock & Unirtenupled \\
\hline$\frac{1200 \mathrm{PST}}{1200 \mathrm{PT}}$ & 27 Jul & $53.43 .5 \mathrm{~N}$ & $\frac{13903.0 \mathrm{~W}}{}$ & 297 & $\frac{1.5}{14.0}$ & Capbeain Interviow 0900 & Moderate Soa & Polar Star & 193 & Sat Lock & Unimaneptod \\
\hline 1200 AST & 28 - $|u|$ & $56-13.6 \mathrm{~N}$ & $148.16 .3 W$ & 292 & 15.0 & E-mail & Moderate Sea & Polar Star & 193 & Sat Look & Uninterupted \\
\hline $1200 \mathrm{AST}$ & $29 \sqrt{41}$ & $55-05.7 \mathrm{~N}$ & $156-34.7 \mathrm{~W}$ & 233 & 7.4 & & Moderato Seat & Polar Star & 193 & intemittant & $2 \min$. \\
\hline 1200 AST & 29vل & $55-05.7 \mathrm{~N}$ & $156-34.7 \mathrm{~W}$ & 223 & 7.4 & Ensign Inteniew 0900 & Mhoderate Ses & NASA POratole & 183 & $\frac{140-210}{10}$ & Uninterenpted \\
\hline $1200 \mathrm{AST}$ & $30 . \sqrt{41}$ & $57-06.9 \mathrm{~N}$ & $152-00.0 \mathrm{~W}$ & 000 & 13.0 & E-mait & Calm Soa & NASA Portaible & 193 & $200-230$ & Unintonupted \\
\hline 1200 AST & 31 - 1 Lal & $56 \mathrm{~N}$ & $152 \mathrm{~W}$ & Kodiax & Docked & E-mail & Lovel sea & Poler star & 193 & Lok PoOK & No Connection \\
\hline 1200 AST & 1. Aug & $56 \mathrm{~N}$ & $152 W$ & Kodiak & Docked & Live From Kodiak 1300 & Lovel sea & NASA Portabie \& Land & 65 & $280-390$ & Uninterupted \\
\hline 1200 AST & $\frac{1}{1-A L g}$ & $56 \mathrm{~N}$ & $152 \mathrm{~W}$ & Kodiak & Docked & Nénorik Tast & Level Soa & Router to Router & Ships Lan & Excollent & Unintensped \\
\hline $1200 \mathrm{AST}$ & 2.Aug & $56 \mathrm{~N}$ & $152 w$ & Kodiak & Docked & E-mail & Lewey Soa & Phone Ine & 193 & Exoellert & Unirtiongted \\
\hline $2000 \mathrm{AST}$ & 3-Aung & $56-22.7 \mathrm{~N}$ & $153.50 .3 \mathrm{~W}$ & $\frac{233}{233}$ & 15.3 & E-mail & Moderate Soa & NASA Portabie & 193 & $0-6$ & $5 \min$ \\
\hline $1200 \mathrm{AST}$ & $\frac{1}{4-A \operatorname{lng}^{2}}$ & $54.20 .7 \mathrm{~N}$ & $159.50 .2 \mathrm{~W}$ & 261 & 15.5 & E-mail & High Ses & NASA Portable & 193 & No Lock & $\mathrm{cmin}_{\mathrm{min}}$ \\
\hline 1200 AST & 5.Aig & $56-59.4 \mathrm{~N}$ & $166-26.5 \mathrm{~W}$ & 346 & 15.2 & E-mail & Moderate sea & NASA Portable & 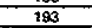 & 0.70 & $4 \min$ \\
\hline $1200 \mathrm{AST}$ & 6-Awg & $6239.9 \mathrm{~N}$ & $167.15 .2 \mathrm{~W}$ & 009 & $\frac{1.2 .3}{14.3}$ & Nonwork Tast & Moderate Soa & Rosters to houtter & Ships LAN & Excollent & Uniterupted \\
\hline$\frac{12 W \mathrm{ASI}}{1200 \mathrm{AST}}$ & $\frac{1}{6 \cdot \text { Ang }}$ & $\frac{1}{62.39 .9 N}$ & $167-15.2 \mathrm{~W}$ & $\frac{100}{109}$ & 14.3 & Live From Nome & Moderate Sog & NASA Portable 0 Land & 193 & 70.130 & Unteruptad \\
\hline 1200 AST & 7.Aug & $66.20 .9 \mathrm{~N}$ & $168-20.1 \mathrm{~W}$ & 355 & 15.8 & Sheiba interviow: Tucker & Moderate Sag & NASA Portable & 193 & 0.50 & $10 \mathrm{~min}$ \\
\hline 1200 AST & 8.Aus & $71-00.4 \mathrm{~N}$ & $16 \mathrm{1} 40.0 \mathrm{~W}$ & 048 & 14.2 & E-meil & Moderato Sea & NASA Portable & 193 & 0.40 & $10 \mathrm{~min}$ \\
\hline 1200 AST & 9-Aug & $72-59.7 \mathrm{~N}$ & $157.19 .9 \mathrm{~W}$ & 000 & 12.2 & $E-m$ ail & tce Filled Sea & NASA Portable & 1903 & 0.50 & $8 \min$ \\
\hline 1200 AST & 10 -Aug & $76-03.1 \mathrm{~N}$ & $157.56 .2 \mathrm{~W}$ & 339 & 9.5 & E-mail & keo Filled Sea & NASA Portable & 193 & 0.50 & $6 \mathrm{~min}$ \\
\hline 1200 AST & $11 \cdot$ Avg & $78+13.6 \mathrm{~N}$ & $158.06 .3 \mathrm{~W}$ & 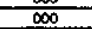 & 6.0 & $E$-mall & Frozen Sea & NASA Portable & 793 & 0.50 & 5 min \\
\hline $1200 \mathrm{AST}$ & 12-ALg & $78.40 .0 \mathrm{~N}$ & $159-12.4 \mathrm{~W}$ & $\frac{51}{321}$ & 3.9 & Sheiba Intenvew: Petrontich & Frozen Sea & NASA Portablo & 193 & 0,0 & $5 \mathrm{~min}$ \\
\hline 1200 AST & 13-ALg & $7.59 .0 \mathrm{~N}$ & $158-03.9 \mathrm{~W}$ & 150 & DIW & Sheiba Imtenvew: Petroviteh & lea Filled Sea & NASA POTtále & 193 & 0.50 & $12 \mathrm{~min}$ \\
\hline $1200 \mathrm{AST}$ & $14 . \mathrm{Awg}$ & $76.43 .6 \mathrm{~N}$ & $157-18.1 \mathrm{~W}$ & 181 & 2.9 & Sheiba Intsendow: Patrovitch & too Filled Sea & NASA Portable & 193 & $0-\infty$ & $4 \mathrm{~min}$ \\
\hline 1200 AST & 15.Aug & $74-58.4 \mathrm{~N}$ & $156-53.7 \mathrm{~W}$ & 184 & 7.5 & Email & Moderate Sos & NASA POAtable & 193 & 0.70 & $4 \min$ \\
\hline 1200 AST & 16 Ang & $71.27 .7 \mathrm{~N}$ & $150-55.1 \mathrm{~W}$ & 177 & 5.5 & Email & Mosiontio Sea & Polar stors & 393 & intemitant & $7 \min$ \\
\hline 1200 AST & 16-ALg & $71 \cdot 27.7 \mathrm{~N}$ & $156.55,1 \mathrm{~W}$ & 177 & 5.5 & Batow Test & Moderato Sea & NASA Portable & 793 & 0.70 & $7 \min$ \\
\hline 2000 AST & 17.Aug & $71 \cdot 19.5 \mathrm{~N}$ & $156 \cdot 45 \mathrm{AW}$ & $\infty$ & 8.5 & Impressions of Bamowr Bates & Moserato Soa & NASA POrtable & 183 & 0.70 & $10 \min$ \\
\hline 1200 AST & 18 -Aug & $72.36 .8 \mathrm{~N}$ & $152.49 .4 \mathrm{~W}$ & 043 & 2.5 & Esmail & $\log _{\text {fillod Sod }}$ & NASA Portablo & 193 & $50-70$ & $10 \mathrm{~min}$ \\
\hline $800 \mathrm{AST}$ & 19Aug & $74.52 .3 \mathrm{~N}$ & $145 \cdot 27.3 \mathrm{~W}$ & 335 & 0.5 & Remoks aoet Test in & $\begin{array}{l}\text { Frozen Sag } \\
\text { Fon }\end{array}$ & NASA Portable & $193 \& 65$ & $60-90$ & $40 \mathrm{~min}$ \\
\hline 1200 AST & 20 -Aug & $74-58.0 \mathrm{~N}$ & $145.50 .7 \mathrm{~W}$ & At Sea & $D W$ & Email & \begin{tabular}{|l|} 
Le Filled Soa \\
\end{tabular} & NASA Portele & 193 & $50+100$ & $20 \mathrm{~min}$ \\
\hline 1200 AST & $21-A w g$ & $72-30.2 \mathrm{~N}$ & $153-13.1 \mathrm{~W}$ & 216 & 10.3 & E-mail & Mocerate Sea & NASA Portable & 193 & $40-50$ & 10 min \\
\hline 1200 AST & 22 -Aug & $\frac{1000.6 \mathrm{~N}}{71+2.3 \mathrm{~N}}$ & $156.48, \mathrm{BW}$ & Anctioned & Anchored & Berrow Tost "l2 & Calm Soa & NASA PO table & 193 & $50-90$ & $10 \mathrm{~min}$ \\
\hline 1200 AST & $23 . \mathrm{Aug}$ & $70.59 .8 \mathrm{~N}$ & $15833.9 \mathrm{~W}$ & Anchored & Anchored & Fomote Boat Tast *2 & \begin{tabular}{|c|} 
Moderato Siea \\
\end{tabular} & NASA Portabie & $123 \& 65$ & $40-70$ & $\$ 0 \min$ \\
\hline 800 AST & 24-Ang & $70-55.6 \mathrm{~N}$ & 159.12.3w & $\frac{243}{243}$ & 7.6 & E.rnail & Nodernto Ses & Polar Star & 189 & intemitiont & $7 \operatorname{mmn}$ \\
\hline DODAST & $\frac{24-A \cup g}{24-4}$ & $70-55.6 \mathrm{~N}$ & $159 \cdot 12.3 \mathrm{~W}$ & 243 & 7.6 & Intervery ota & Mocerate Seat & Portable & 993 & 0,40 & $0 \min$ \\
\hline 1200 AST & 25.Ang & $70-55.6 \mathrm{~N}$ & $\frac{159-12.3 W}{15 W}$ & Anchored & Anchomed & E-mail & Mocorato Ses & Polar Star & 103 & Intermittant & 5 min \\
\hline 1200 AST & $25 . A 49$ & $70-55.6 \mathrm{~N}$ & $15.12 .3 \mathrm{~W}$ & Anctioned & Anctronod & intervien. Hope & \begin{tabular}{|l|} 
Moderate Sea \\
\end{tabular} & Portable & 193865 & $0-60$ & $2 \min$ \\
\hline $\begin{array}{l}1200 \text { AST } \\
1200 \text { AST }\end{array}$ & $\frac{25+A B Q 9}{26-A u g}$ & $\frac{10-5.6 \mathrm{~N}}{70-55.6 \mathrm{~N}}$ & $\frac{1059123 W}{159-12,3 W}$ & Anchored & Anctioned & E,mail & Mocorate Sea & Polar stat & 193 & Imtomsiltant & $4 \min$ \\
\hline$\frac{1200 \mathrm{AST}}{1200 \mathrm{~T}}$ & 26. Aug & $70-55.6 \mathrm{~N}$ & $159-12.3 \mathrm{~W}$ & Anchored & Anctioned & Interview: Weast & Mocierato Ses & Portable & 193865 & 60.80 & $60 \min$ \\
\hline 1200 AST & $27 . A 4 g$ & $71-17.8 \mathrm{~N}$ & $156-54.9 \mathrm{~W}$ & Anchored & Anchoried & E-mail & Mojorate Sea & Polar star & 65 & Intermittant & $10 \mathrm{mkn}$ \\
\hline 1200 AST & $27-A n g$ & $71-17.8 \mathrm{~N}$ & $156.54 .9 \mathrm{~W}$ & Axchored & Anchored & Interview: Durbes & Modorate Sea & Portable & 65 & $70-110$ & $80 \min$ \\
\hline 1200 AST & $28 \cdot \overline{A v g}$ & $70-54.9 \mathrm{~N}$ & $159-18, \mathrm{DW}$ & Anchored & Anchosied & & Moderato Saa & Polar Star & 193 & No Sat Lock & $0 \min$ \\
\hline$\frac{1200 \mathrm{AST}}{1200 \mathrm{AST}}$ & 28-Aug & $70.54 .8 \mathrm{~N}$ & $159 \cdot 18,0 \mathrm{~W}$ & Anchored & Anchored & Inteniow: gilleaucoaux & Moderato Sea & Portabie & 193 & 0.40 & $0_{\min }$ \\
\hline
\end{tabular}

